\title{
COMMENTS
}

\section{CONTRIBUTIONS OF INDIAN AUTHORS IN THE SUBJECT CATEGORY LAW OF THE WEB OF SCIENCE CORE COLLECTION: A BIBLIOMETRIC ANALYSIS}

\author{
DEEPAK KUMAR, \\ Central University of Punjab (Bathinda, India) \\ BHUPINDER SINGH, \\ Central University of Punjab (Bathinda, India)
}

https://doi.org/10.21684/2412-2343-2020-7-2-148-156

This paper presents a bibliometric analysis of research works in the subject category Law published with the affiliation of India in the Web of Science Core Collection. A total of 529 published works by Indian authors from Indian law schools and institutions on or relating to the subject of the law have appeared in law journals and other sources. The works are indexed in the Core Collection for the years 1999-2019 and have been cited 2,041 times over this 20-year period. To conduct the analysis of the published data based on norms such as author-wise, country-wise and citation-wise figures, normative bibliographic techniques were applied to attain the objectives. After a detailed discussion of the analysis of the data, the research arrives at the conclusion that Indian authors have fewer published works in the subject category Law in the Core Collection than two other Asian countries, but that there has been a gradual increase in their number since 2011.

Keywords: bibliometric; higher education; Indian authors; law; citation references; publications.

Recommended citation: Deepak Kumar \& Bhupinder Singh, Contributions of Indian Authors in the Subject Category Law of the Web of Science Core Collection: A Bibliometric Analysis, 7(2) BRICS Law Journal 148-156 (2020). 


\section{Introduction}

A higher education system covers the final level of education and comprises the universities and advanced institutions of instruction in such fields as technology, medicine, science, the humanities and social sciences, languages and law. A developed and fully established education system is a pre-requisite for any welfare state that aspires to social and economic growth and recognition at the global level. The universities and higher-level educational institutions are the torch-bearers for the modern system of education and research and have the responsibility to be at the forefront.

With the increasing competition in the field of legal education at the national, regional and international levels, and with the limited availability of public and private funding for education and research, the measurement of productivity is becoming ever more important for potential students, education administrators, policymakers and funding organizations. Each year, various agencies prepare standards by which to evaluate universities and institutions on different parameters of teaching and research. One of the important parameters for evaluating an institution is its research output. The level of development of educational institutions can be revealed by the quality of research outputs in such ways as the number of research works published and the number of patents acquired, among others. Of these, published research works is one of the parameters that can reliably show the research output of any state, university, institution - or even of a person. In the field of the law, the Web of Science bibliographic database maintains an index known as the Core Collection, and the subject category Law, which covers journals and other sources specializing in the law.

This study is an attempt to explore the research output of Indian authors for the years 1999 to 2019 on the basis of publication data available in the Web of Science Core Collection subject category Law. An attempt is also made to understand the different dimensions of research output by analyzing different parameters such as yearly publications, topranked journals, author's affiliations and patterns of communication.

\section{Review of the Literature}

Many research scholars have published their respective findings based on norms such as citations, h-index, author affiliation, type of resources, etc. Garg and Kumar (2014) analyzed 9,957 works indexed in the Web of Science Core Collection and published by Indian researchers in the disciplines of the life sciences. The results reveal that a majority of works are published by a male and female co-authorship pattern. 'Another study (Gupta, Gupta, Kshitij and Bala, 2014) focused on glaucoma research by Indian authors in the period 2002-2011. The study revealed the citation

Kailash Chandra Garg \& Suresh Kumar, Scientometric Profile of Indian Scientific Output in Life Sciences with a Focus on the Contributions of Women Scientists, 98(3) Scientometrics 1771 (2014). 
impact per published work registered by Indian publications. ${ }^{2}$ Khanna, Singh, Tewari and Saini (2017) studied the research contributions of the Guru Nanak Dev University, Amritsar in physics and astronomy during the period 2006-2015 published in Scopus indexed journals. The study analyzed the year-wise research productivity, the national and international collaborations, the top collaborating institutions, the most prolific authors, the journals used for communication, the most preferred journals for publication and the number of citations received. ${ }^{3}$ Dutt and Brar (2018) mapped the output and citation analysis of research activities in engineering in the 2002-2016 period. The study analyzed the number of publications, citation analysis, research output and h-index. ${ }^{4}$ Suresh and Babu (2019) investigated the research works in agronomy published in the Scopus database during the period from 1956 to 2017. The analysis covered year-wise, category, authorship and countrywise distribution of articles. ${ }^{5}$ Singh, Bawa and Singh (2016) studied the bibliometric analysis of literature published with the affiliation of India in the Arts \& Humanities Citation Index (A\&HCI) of the Web of Science Core Collection from 1999 to 2017. Indian authors of works appearing in 3,234 publications received 5,138 citations. ${ }^{6}$

This study was based on the factors author-wise, country-wise or citation-wise. Some studies analyzed occurrence patterns, some co-authorship patterns, and some bibliometric coupling. From the above review of the literature, one may observe that the majority of bibliometric studies have been conducted in a science discipline and a gap can be seen in the field of the law.

The present study focuses on the discipline of the law with all patterns.

\section{Objectives of the Study}

Undermentioned objectives are framed to study the research outcomes of Indian authors in the Web of Science Core Collection subject category Law:

- To explore the growth of Indian published works in law among the Asian countries;

- To study the distribution of the type of law in the published works;

2 Ritu Gupta et al., Glaucoma Research: A Scientometric Study of Indian Publications Output, 2002-11, 34(1) DESIDOC Journal of Library and Information Technology 35 (2014).

3 Sunaina Khanna et al., Scientometric Analysis of the Research Output of Physics and Astronomy of Guru Nanak Dev University During 2006-15, 37(5) DESIDOC Journal of Library and Information Technology 337 (2017).

4 Mahipal Dutt \& Khushpreet Brar, Research Output and Citation Analysis of Leading Global Engineering Research Countries During 2002-16, 5(2) GNIMS - International e-Journal of Library Science 83 (2017).

5 C. Suresh \& V. Ramesh Babu, Scientometric Study of the Research Performed on Agronomy: The Indian Perspective, Library Philosophy and Practice 2573 (2019).

6 Bhupinder Singh at al., Contribution of Indian Authors in Web of Science: Bibliometric Analysis of Arts \& Humanities Citation Index (A\&HCI), 6(5) International Journal of Library \& Information Science 10 (2017). 
- To make a brief analysis of the occurrences and trend of Indian researchers' published works in the Web of Science Core Collection subject category Law;

- To identify the source types of the published works which are cited more often in the Web of Science Core Collection subject category Law;

- To examine the contribution of Indian authors in the Web of Science Core Collection subject category Law.

\section{Methodology}

The subject category Law from 1999 to August 2019 accessible on the Web of Science database was studied to arrive at the research output. To gather the data for the study, an online search was conducted in the Web of Science Core Collection subject category Law during the last week of August 2019 using the Field Tag WC=LAW. A total of 529 published works were identified having affiliation with India. Full bibliographic detail is available for these records in the Web of Science Core Collection subject category Law. A number of separate files were created for the types of the publications, authors' names, journal names, etc., for the 529 published works.

\section{Results and Discussion}

As reflected in the subject category Law database, a total of 529 published works were available in the database during the period 1999-2019 where the Field Tag was WC=LAW. As presented in Table 1 below, based on the country-wise data of a number of works published during the period under study, India ranks third in Asian countries with China and Israel ranked first and second, respectively.

Table 1: Publication details of the Top 10 Asian Countries in the Web of Science Core Collection subject category Law from 1999 to 2019

\begin{tabular}{|l|c|c|c|c|}
\hline Country & $\begin{array}{c}\text { Number } \\
\text { of published } \\
\text { works }\end{array}$ & h-index & $\begin{array}{c}\text { Sum of } \\
\text { times cited }\end{array}$ & $\begin{array}{c}\text { Average number } \\
\text { of citations } \\
\text { per published work }\end{array}$ \\
\hline China & 1,677 & 25 & 4,872 & 2.91 \\
\hline Israel & 855 & 37 & 8,419 & 9.85 \\
\hline India & 529 & 29 & 2,041 & 3.86 \\
\hline South Korea & 403 & 13 & 1,173 & 2.91 \\
\hline Singapore & 368 & 17 & 1,366 & 3.71 \\
\hline Japan & 347 & 19 & 1,703 & 4.91 \\
\hline Taiwan & 238 & 15 & 1,081 & 4.54 \\
\hline Turkey & 144 & 12 & 494 & 3.43 \\
\hline Malaysia & 114 & 9 & 225 & 1.97 \\
\hline Thailand & 59 & 6 & 288 & 4.68 \\
\hline
\end{tabular}


One of the importent indicators of the quality or impact of the published works is the number of citations the works received in other research studies. On this parameter, India ranks fifth among Asian countries with 3.86 citations per published work, as shown in Table 1, and Israel ranks first with 9.85 average citations per published work. A total of 529 works by Indian authors were cited 2,041 times, while 855 works by Israeli authors were cited 8,419 times.

The 529 works were published over a period of 20 years, and, on average, 25 works were published yearly, with a steady increase in the number of works published each year as shown in Figure 1 below. At the beginning of our dataset, i.e. in 1999, only 5 works were published with the affiliation of India, while in 2018 this number rose to 25 published works, with the highest number of 66 in 2008, thereby showing a fourfold increase on a quantitative basis as depicted in Figure 1.

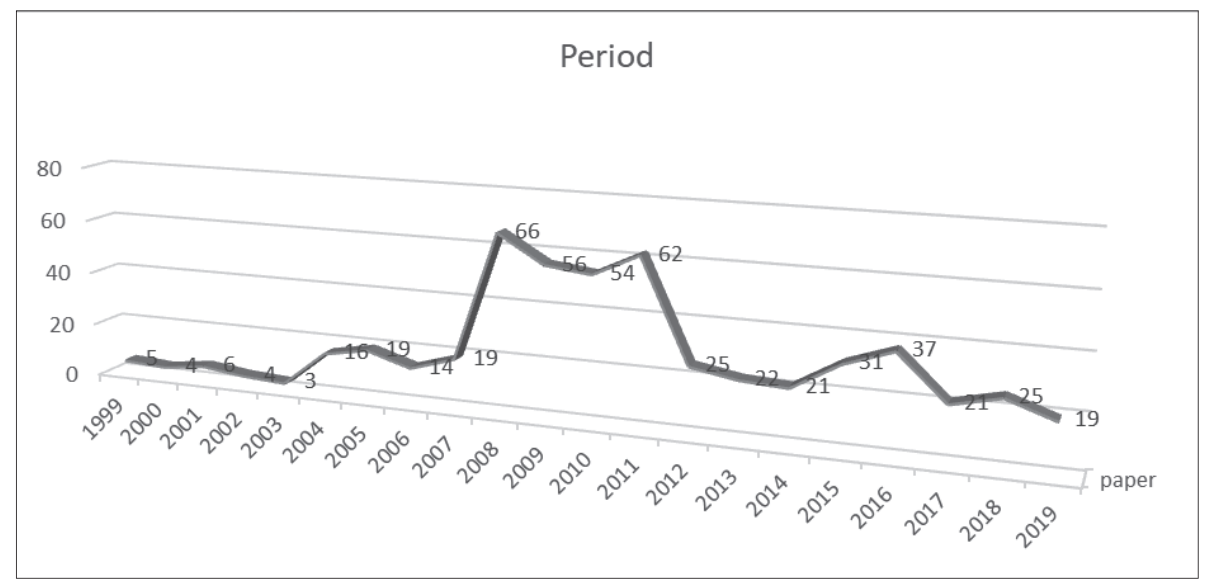

Figure 1: Growth of Indian published works in the subject category Law, 1999 to 2019

Published works are not limited to research articles only and can appear in a number of other forms such as reviews, proceedings papers, editorial material, etc. Figure 2 below displays the publication type-wise distribution of the 529 works published during 1999-2019 and indexed in the subject category Law. The types of the published works are: articles - 459 (86.77\%); book reviews - 32 (6.05\%); editorial material - 23 (4.35\%); reviews - 10 (1.89\%); proceedings papers - 4 (0.76\%) [and, others $-1(0.19 \%)$ ], as indicated in Figure 2. 


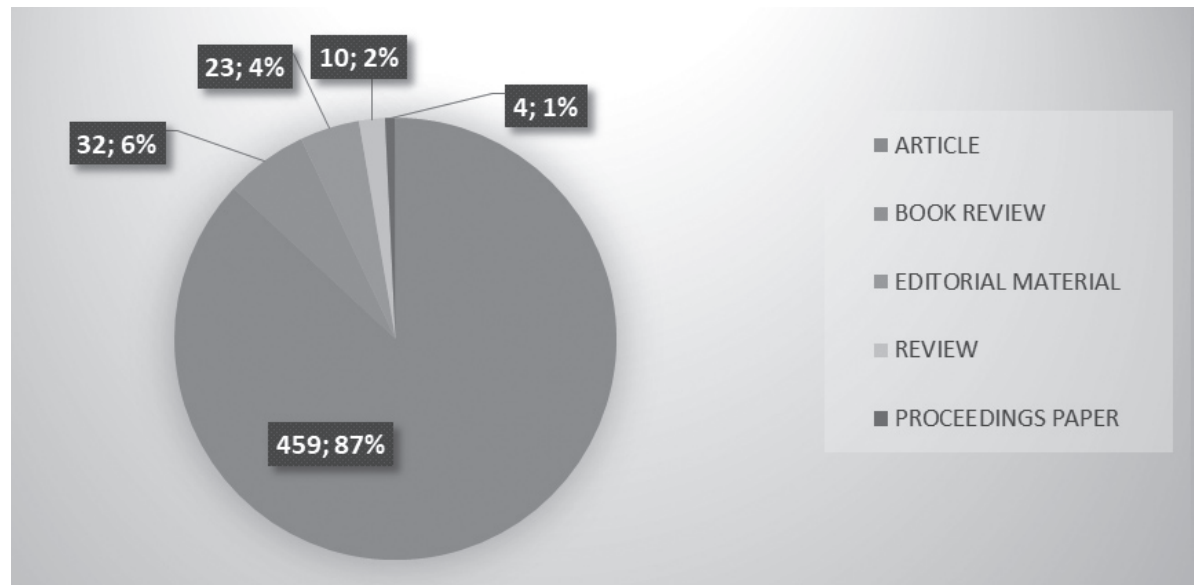

Figure 2: Distribution of published works by type

The 529 published works were cited 2,041 times, with 3.86 average citations per work. A breakdown of the average number of citations per work for different content types reveals that reviews were the most cited form with 100 citations and 10 citations per work on average. The number of citations for articles was 1,872 with 4.08 average citations per work, and proceedings papers with 28 citations and an average of 7 citations per work as displayed in Figure 3 below. Book reviews and editorial material were the least cited types of published works.

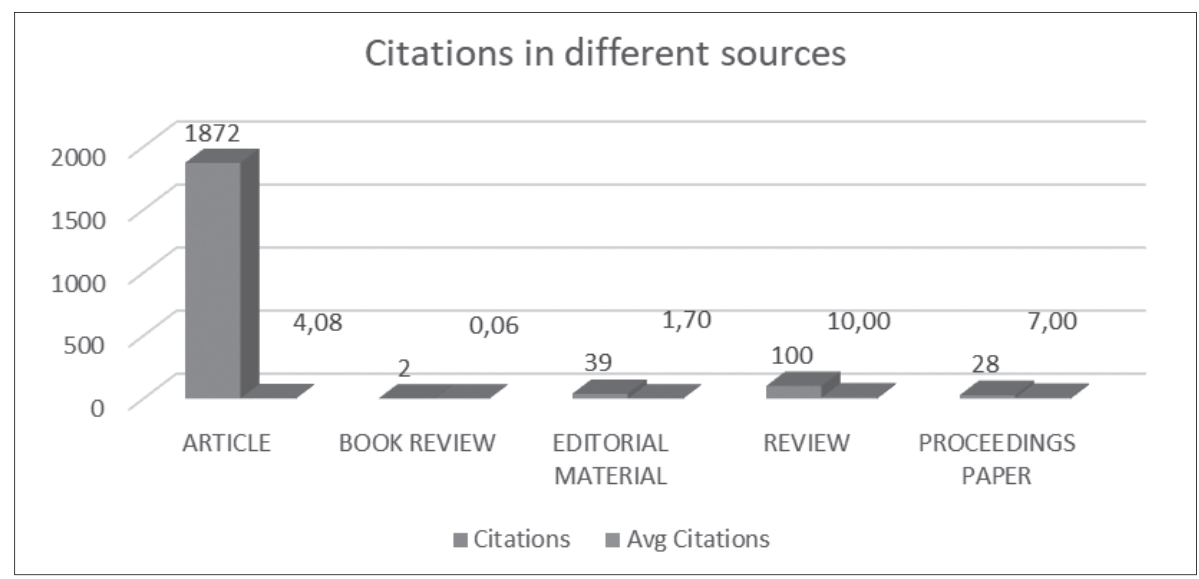

Figure 3: Total citations and average number of citations 
The total number of citations received was 2,041 for 529 works published in the subject category Law during the period from 1999 to 2019. The average number of citations received per published work was 3.86. In 2017, 12.95 was the average number of citations received per published work, and 11.20 the average number of citations received per publication.

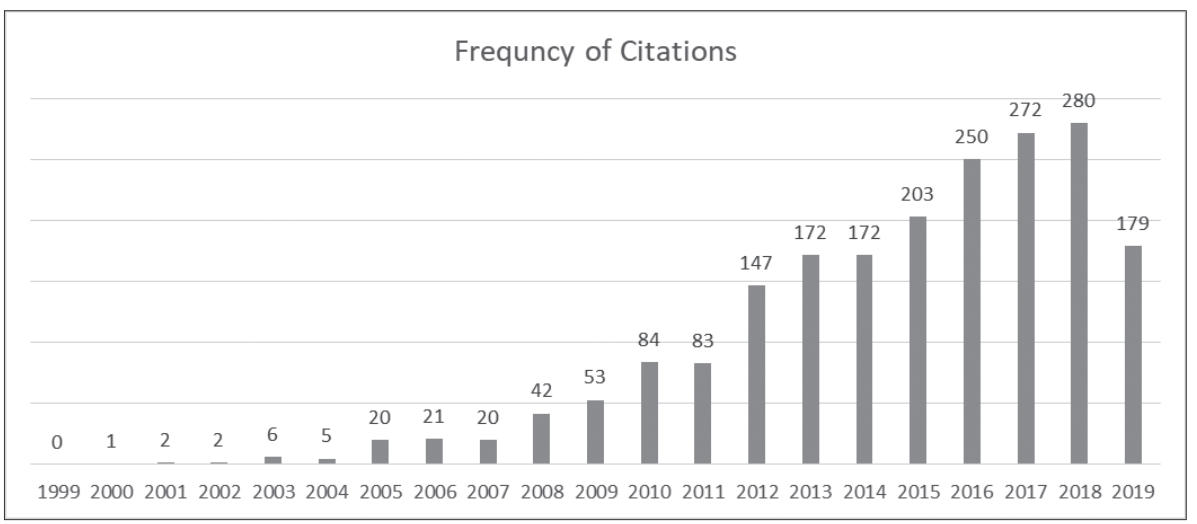

Figure 4: Indian-affilation published works in the Web of Science Core Collection in the subject category Law

Based on the number of published works in the subject category Law, it was found that 6 journals published 356 works and the total cumulative published output by India during 1999-2019 amounted to $67.30 \%$. The most recurrent journal was the Journal of Intellectual Property Rights, which published 155 works, followed by Medicine Science and The Law with 144 works by Indian authors in the subject category Law from 1999 to 2019, as revealed in Table 2 below.

Table 2: List of the major journals in the Web of Science Core Collection subject category Law 1999-2019

\begin{tabular}{|l|c|}
\hline Journal & Works \\
\hline Journal of Intellectual Property Rights & 155 \\
\hline Medicine Science and the Law & 144 \\
\hline Journal of World Trade & 23 \\
\hline Washington Quarterly & 14 \\
\hline Asian Journal of WTO International Health Law and Policy & 10 \\
\hline Computer Law Security Review & 10 \\
\hline
\end{tabular}


Based on the publications output data for Law, 8 Indian authors were identified who had more than 10 published works in the Web of Science database under the subject category Law from 1999 to 2019. These authors (listed in Table 3 below) altogether contributed 111 works (20.98\%). The average number of citations of the authors during 1999 to 2019 was 6.33 per author and per published work citation 5.89. These authors were: L. Rajamani, with 24.92 average citations per work; B.R. Sharma, with 8.00; R. Rautji, with 5.91; and T.D. Dogra, with 5.53, as shown in Table 3.

Table 3: List of authors with the highest number of published works in the subject category Law, 1999-2019

\begin{tabular}{|l|c|c|c|c|}
\hline Author & $\begin{array}{c}\text { Published } \\
\text { works }\end{array}$ & h-index & Citations & $\begin{array}{c}\text { Average number } \\
\text { of citations }\end{array}$ \\
\hline C. Behera & 18 & 4 & 70 & 3.89 \\
\hline M.D. Nair & 18 & 1 & 11 & 0.61 \\
\hline R. Rautji & 16 & 6 & 93 & 5.91 \\
\hline T.D. Dogra & 15 & 6 & 83 & 5.53 \\
\hline L. Rajamani & 12 & 10 & 299 & 24.92 \\
\hline Z. Thomas & 12 & 0 & 0 & 0.00 \\
\hline S. Kochhar & 10 & 3 & 18 & 1.80 \\
\hline B.R. Sharma & 10 & 5 & 80 & 8.00 \\
\hline
\end{tabular}

\section{Conclusion}

India has very good academic and administrative infrastructure and facilities for teaching and research in the law. Yet, the analysis of the data from the Web of Science database shows that the number of published works in the subject category Law from India is less than that of some other Asian countries. Since 2011, however, the number of these works from India demonstrates a gradual increase. Indian authors are more motivated to publish research articles purely in the field of the law rather than in allied or interdisciplinary fields.

The discussion in this research also explored a trend adopted by Indian authors to publish their research output or materials in Indian publications, as noted by the fact that there were a total of 1,872 published works cited in the Web of Science Core Collection in the subject category Law during 1999-2019, while only 67 works were contributed by four Indian authors.

It is also clear from the analysis that Indian authors are contributing a lot in terms of published legal research work, but most of the journals their works appear in are not listed in the Web of Science Core Collection subject category Law, which is something that has become a limiting factor for wider dissemination of their 
research output. Logically, it may be said that there is lack of awareness. And, as a recommendation, it may be said that Indian authors and publishers who are working in the field of the law should be made better aware of the publications indexed in the Web of Science.

Adoption of the relevant technology is also required, for in the present era of information technology there has been a strong demand and proliferation of online journals and research databases. In India, a large number of Indian journals in the field of law still publish in print form, a circumstance that places Indian journals beyond the reach of computerized research databases and indexes, with the result that their reference citations are not being counted nor appearing in citation counting techniques. In the field of the law, primarily online versions of print journals should be encouraged and, secondly, a separate citation index system for print-only journals should be developed, which will help in assessing the contributions of all authors and researchers working in the field of the law.

\section{Acknowledgements}

It gives us great pleasure to express our thanks publicly to all of the people whose work helped us in writing this research paper. We would also like to thank Central University of Punjab, Bathinda for providing the opportunity and environment that enabled our research on the approach and perceptions of bibliometrics analysis. We extend our deep sense of gratitude and sincere appreciation to each and every person whose suggestions, support and cooperation aided us in this endeavor.

\section{Information about the authors}

Deepak Kumar (Bathinda, India) - Associate Professor, Department of Law, Central University of Punjab (Bathinda, Punjab, 151001, India; e-mail: drdeepakkumar chauhan@gmail.com).

Bhupinder Singh (Bathinda, India) - Assistant Librarian, Central University of Punjab (Bathinda, Punjab, 151001, India; e-mail: bhupinder82@gmail.com). 